\title{
EL MEJOR DINERO POSIBLE
}

\author{
LUIS CARLOS SÁNCHEZ MARTÍNEZ*
}

\section{I \\ INTRODUCCIÓN}

Los seres humanos se intercambian libremente productos y servicios en el mercado. El uso del dinero sustituyendo al trueque facilitó la multiplicación de los intercambios. Los productos que fluyen al mercado son libremente escogidos por los individuos, pero no ocurre lo mismo con la moneda utilizada que viene indicada por los gobiernos. Resulta contradictorio que el instrumento más eficaz para el intercambio voluntario sea impuesto por los gobiernos y no sea resultado del acuerdo voluntario de los individuos, lo que impide que los ciudadanos puedan elegir la moneda más eficaz.

El dinero surgió de forma espontáneo pero no casual. En diferentes puntos del planeta y en diversos períodos de tiempo surgieron monedas que facilitaban un intercambio de productos y servicios mucho más eficaz que con el trueque. Como toda innovación humana fue mejorando a lo largo del tiempo y diferentes bienes desempeñaron la función monetaria. Al final fueron los metales preciosos, especialmente el oro, los que se alzaron como los preferidos para ser utilizados como dinero.

Después surgieron otros bienes que sin apenas valor pasaron a ser utilizados como moneda como el caso del papel o las anotaciones de cuenta. La existencia de un dinero sin respaldo en bien tangible alguno ha levantado numerosas suspicacias. Se le achaca que su aceptación entre los agentes acostumbrados a operar con monedas con respaldo se debió principalmente a la coacción estatal. No entienden otra forma de aceptar bienes sin apenas valor. ¿No podría ser que el dinero fiduciario fuera más eficiente?

* E-mail: correo@luiscarlos.es 
Cuando el oro actuaba como dinero su valor estaba compuesto por sus dos usos: el intrínseco del metal y el monetario. Éste último era fiduciario, es decir, se basaba en la fe de que el oro iba a ser aceptado para el intercambio comercial. Lo que ocurre con el actual dinero fiduciario es que el valor del material es ínfimo y la mayor parte de su valor total descansa en la utilidad que proporcione para facilitar las transacciones entre agentes. El dinero mercancía fue fructífero hasta que pasó a ser proporcionado por los gobiernos. No podemos juzgar al dinero sin respaldo material sólo por los ejemplos gestionados por el estado, igual que tampoco lo haríamos con el dinero mercancía. El dinero fiduciario puede existir sin ningún tipo de respaldo estatal y ser el mejor dinero posible.

La problemática de la actuación sobre el dinero depositado en los bancos se produce para cualquier tipo de moneda de referencia. La cuestión radica en conocer si la actuación de las entidades de crédito influye en el valor del dinero en circulación. Las actuales políticas monetarias así lo estiman y por esa razón influyen en los tipos de interés vigentes. Pero si la premisa sobre el dinero depositado fuera falaz, nos encontraríamos con que los tipos de interés podrían venir determinados por las necesidades de los agentes presentes en el mercado de crédito.

El actual dinero se deprecia constantemente y su inestabilidad provoca un importante perjuicio a la economía. Un dinero fiduciario dota al mercado de un instrumento eficaz para el intercambio y un dinero independiente lo dota de una moneda segura, previsible y valorada. El dinero fiduciario privado se alza como una herramienta eficaz para mejorar los intercambios comerciales.

II ¿QUÉ DINERO HEMOS TENIDO?

El uso del dinero para sustituir al trueque es antiquísimo. En la antigüedad, diversas tribus de Asia y Âfrica utilizaban conchas de mar o monedas de sal para su comercio. En la América precolombina se utilizaba el cacao como moneda, los lacedemonios 
utilizaban el hierro, los primeros Romanos eligieron el cobre, en Terra-Nova el bacalao y, durante un largo período de tiempo, el oro y la plata.

Al principio estos dineros eran proporcionados por particulares hasta que el Estado se arrogó la potestad exclusiva de emitir moneda. Con su participación se produjo el descontrol de la masa monetaria debido a las rebajas de valor que realizaban los gobiernos como el caso denunciado por Juan de Mariana en su obra «Tratado y discurso sobre la moneda del vellón». Estas rebajas no sólo eran impuestos ocultos que suponían una transferencia de recursos de los ciudadanos hacia los gobiernos, sino además introducían desconfianza y recelo en el valor de la moneda con el peligro que suponía sobre las transacciones comerciales.

Pero la rebaja más definitiva sobre el metal que llevaban las monedas se perpetró en la cita de Bretton Woods, donde se eliminó la última ligazón entre los billetes emitidos por el Estado y los metales preciosos. A partir de aquella fecha el dinero emitido no tenía más respaldo que la confianza depositada en su aceptación por el resto por lo que se denominaba fiduciario.

Que no hubiera posibilidad de rebajar más la cantidad de metal no ha impedido que el dinero estatal siga perdiendo valor de forma continua y ahora de manera aún más rápida, con el consiguiente lastre para facilitar el intercambio comercial. En el Gráfico 1 podemos comprobar cómo a partir del acuerdo de Bretton Woods la pérdida de poder adquisitivo del dólar ha sido constante y en una proporción sin parejo a lo largo de la historia.

$Y$ eso que el planteamiento de un dinero fiduciario estatal con reglas fijas de funcionamiento tenía el objeto loable de dotar de estabilidad a la moneda. Milton Friedman (1987) planteó que la mejor solución para la estabilidad del dinero era la congelación de la base monetaria. Una cantidad fija de dinero emitido sería equivalente a un oro sin nuevos yacimientos, lo que daría a los agentes la confianza en que no van a existir distorsiones a la hora de realizar sus previsiones. Los agentes sabrían que ningún político ni ninguna proyección estadística modificarían el número de unidades monetarias en circulación. Para lograrlo se planteaba la independencia de los bancos emisores con un funcionamiento previsible para los agentes económicos. 


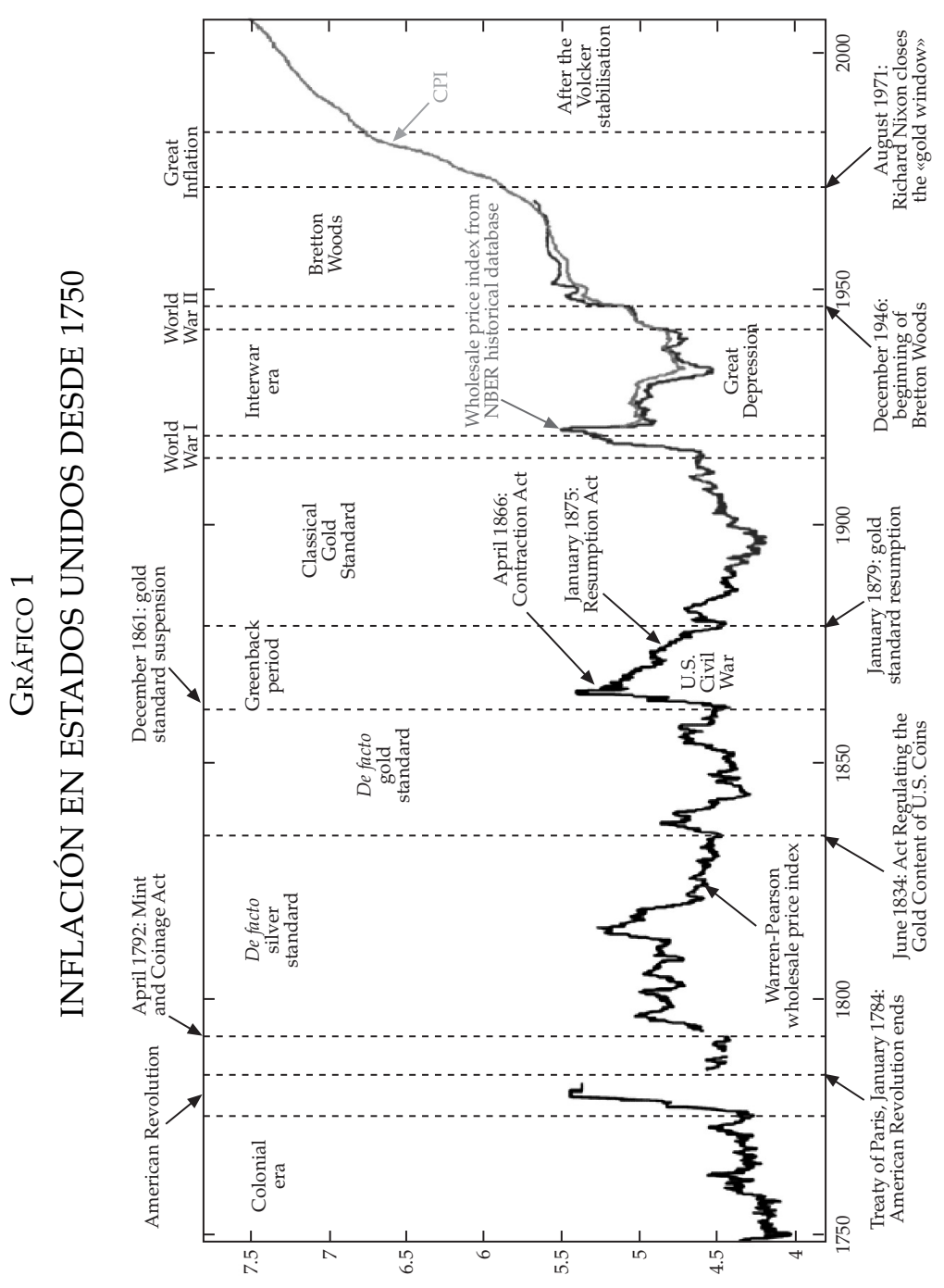

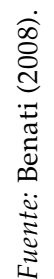


Aunque ningún banco central admite utilizarla, la regla de Taylor (1993) es considerada como una guía útil para la gestión monetaria. Se basa en establecer tipos de interés más elevados cuando la inflación supere su nivel objetivo o cuando la economía crezca por encima de su nivel potencial. Los problemas de aplicación de dicha regla provienen de varios frentes. El primero es que el tipo de interés de equilibrio es variable y no siempre observable. Tratar de fijar el precio de un mercado, en este caso el del crédito, de forma arbitraria supone enfrentarnos al «teorema de conocimiento limitado». ¿Pueden sustituir una docena de doctas personas el conocimiento de millones de individuos sobre sus preferencias y necesidades? Adam Smith (1776) nos advertía de esa misión imposible: «El político que pretenda dirigir a las personas privadas sobre la forma en que deben invertir sus capitales no sólo se carga a sí mismo con la preocupación innecesaria sino que asume una autoridad que no debería ser delegada con seguridad en ninguna persona, en ningún consejo o senado, y que en ningún sitio es más peligrosa que cuando está en las manos de un hombre tan insensato y presuntuoso como para fantasear que es realmente capaz de ejercerla» ${ }^{1}$.

El segundo es que la aplicación de estas normas se realiza mediante cambios en los tipos a corto plazo, cuando estos no tienen una relación fija y directa con los tipos a largo. Un tercer problema es el derivado de la fiabilidad de los índices de precios que se utilizan para la toma de decisiones. Mises (1949) los criticó porque se trata de datos heterogéneos puramente arbitrarios de los que se deducen promedios que no tienen porque coincidir con el precio final. ¿Se imaginan que los gobiernos fueran elegidos mediante encuestas y no por sufragio universal?

La promulgación de estas reglas monetarias se deriva de la teoría cuantitativa del dinero. La conocida ecuación monetaria por la cual todos los bienes y servicios intercambiados en un período a un precio de determinado son igual a la cantidad de moneda emitida multiplicada por las veces que se ha transmitido suele explicarse con el ejemplo de una economía donde sólo se produjera pizzas. En este caso es claro que el valor de todas

${ }^{1}$ [Trad. esp. (2001). La riqueza de las naciones. Madrid, Alianza Editorial, p. 554]. 
las pizzas vendidas será igual al de la cantidad de monedas existentes multiplicadas por las veces que han cambiado de manos. Pero para el establecimiento de las reglas monetarias que rigen el dinero fiduciario público se determinan interpretaciones de cada uno de los componentes de la ecuación que no resultan tan irrefutables.

La misma definición de masa monetaria puede dar lugar a refutaciones como las expuestas en el apartado de este mismo artículo dedicado al dinero bancario. El supuesto de que la velocidad de circulación del dinero es estable plantea serias dudas. También lo plantea considerar como bienes en la ecuación únicamente a aquellos bienes y servicios de consumo: olvida que el dinero también puede ir destinado a otros fines como inmuebles, acciones u otras inversiones con lo que se está rompiendo la igualdad de la ecuación. Además los movimientos generales de precios pueden ser debidos a cambios en la eficiencia productiva y no a cambios en la demanda de saldos en dinero como expone Selgin (1988). Los datos ofrecidos por Friedman y Schwartz (1963) indican una relación directa entre el crecimiento de la masa monetaria y la inflación, pero si desglosamos los datos en función de la inflación podemos comprobar que esa relación sólo se mantiene en países con alta inflación pero no en países con baja inflación (De Grauwe y Polan, 2005).

Si existe un consenso sobre las virtudes de la estabilidad monetaria, no lo hay sobre cómo se alcanza. Aunque tanto las visiones monetarista como austriacas muestran que la inflación es un fenómeno monetario, divergen al definirla. Friedman (1968) consideró que la inflación se producía cuando la cantidad de dinero se elevaba apreciablemente de forma más veloz que como lo hacía la producción. Mises (1912) definió inflación como una disminución del valor objetivo del dinero provocada la existencia de más dinero del necesitado por el mercado. Para el economista austriaco esta variación, así como la derivada del efecto contrario denominado deflación, era normal ya que un valor constante no podría mantenerse a lo largo de mucho tiempo. Ni siquiera aumentando o disminuyendo la cantidad de dinero ya que las causas de esas variaciones son múltiples. 
Estos aspectos señalados anteriormente son los que provocan la pérdida constante de valor del dinero fiduciario estatal e impiden a los agentes de disponer del mejor dinero posible para sus intercambios comerciales. Al operar los emisores de moneda en régimen de monopolio, no existen mecanismos de corrección automáticos de su mala gestión.

III

\section{LA ALTERNATIVA FIDUCIARIA}

Hemos visto la evolución histórica del dinero que nació como mercancía provista por agentes privados para después pasar a ser proporcionado por el estado. Este paso supuso alteraciones continuas del valor del dinero y una transferencia de rentas de los ciudadanos hacía los gobiernos. Aunque esa situación se ha suavizado, la pérdida de valor ha seguido siendo inexorable con el actual dinero fiduciario. Esta experiencia histórica ha llevado a algunas voces a defender el regreso al dinero mercancía sin monopolio estatal, bien mediante el uso de metales preciosos o el de participaciones en fondos de inversión en activos reales (Greenfield y Yeager, 1983). Pero pasan por alto que lo que provoca los fallos del dinero actual no es su carácter fiduciario sino ser provisto monopolísticamente por el estado, quien cuando lo que proveía era dinero mercancía también provocaba una moneda defectuosa.

El paso del patrón oro al dinero fiduciario en Bretton Woods fue una medida arbitrariamente tomada por los gobiernos, pero debemos recordar que no fue el primer cambio de moneda. Desde las conchas de mar hasta el oro se produjeron multitud de cambios. ¿Por qué el oro habría de ser «la última parada»? El oro y el resto de sus antecesores se monetarizaron porque cumplía mejor las características necesarias para facilitar el intercambio comercial.

¿Por qué los individuos los eligieron? Menger enumeró en 1892 las razones por las que se habían convertido en dinero:

- Eran escasos

- Estaban geográficamente bien distribuidos

- Gran divisibilidad 
- Bajo coste de transporte

- Ilimitada durabilidad

- Bajo coste de atesoramiento

El oro y la plata cumplían perfectamente los requisitos que se exigen a un bien para ser un medio generalmente aceptado de intercambio de productos. Pero esos mismos requisitos los cumple aún mejor el dinero fiduciario emitido en billetes y monedas. El no estar respaldado por ningún metal precioso no evita que sean escasos, se puedan distribuir fácilmente en diversos puntos geográficos, se puede fraccionar, tienen un bajo costo de transporte, elevada durabilidad y bajo coste de atesoramiento.

El coste de atesoramiento no es sólo el derivado de su custodia sino también el desembolso necesario para hacerse con el acopio de la mercancía que representará el dinero. Y en ese caso el oro es muchísimo más costoso que los billetes o las anotaciones en cuenta. Una tara que reconocían Hayek (1976) o Mises (1912) cuando auguraba la imposibilidad de la vuelta al patrón oro ya que supondría un incremento del precio del metal y por tanto un descenso del correspondiente al resto de bienes con la siguiente merma patrimonial.

A pesar de las ventajas objetivas del dinero fiduciario, existen autores como Anderson (1925) que expresan su desconfianza del dinero que solo fuese dinero: «¿Por qué habrían de ser aceptados por los productores a cambio de su trabajo o de los bienes que producen con su esfuerzo? ¿Por qué alguien habría de quererlos? En otras palabras, ¿por qué habrían de circular?» ${ }^{2}$

La explicación más sencilla de la aceptación del dinero fiduciario es la existencia de una coacción legal por parte de los Estados. Pero en numerosos mercadillos callejeros asiáticos, africanos y sudamericanos se aceptan monedas emitidas por países occidentales. Incluso los nacionales de esos países utilizan esas monedas extranjeras para intercambios entre ellos y para ahorrar a pesar de que no se encuentran bajo la jurisdicción de sus gobiernos. En el caso de los dólares americanos se calcula que más del

2 [Trad. esp. (2004): «Moneda administrada frente a Patrón oro». Procesos de Mercado, n.․ 1, vol. I, p. 288]. 
$80 \%$ de los billetes emitidos por la Reserva Federal se encuentran fuera de las fronteras estadounidenses.

Otra explicación alternativa se refiere a que son los activos del Banco del Estado los que respaldan la moneda de la misma forma que anteriormente lo hiciera el oro. Dentro de esos activos nos encontraríamos con las reservas en oro, moneda extranjera y títulos de deuda pública con la que contara. Así el actual modelo se parecería a un sistema de monedas respaldadas por materias primas o activos financieros. Pero esa relación no se aprecia en el actual sistema de dinero fiduciario. La valoración de las reservas de los bancos centrales es muchísimo menor que el dinero emitido, por lo que su utilidad para evitar descensos de la cotización de las monedas siempre se encontraría limitada.

El uso de esas reservas para el sostenimiento artificial de un determinado tipo de cambio no puede más que resultar ruinoso para el que lo intente. Las reservas nunca podrán resistir el envite de aquellos que desconfían de la moneda al no poder responder de la totalidad de la emisión. Es por esto que el sistema más beneficioso siempre resulta la libre fijación del precio de la moneda, el tipo de cambio, igual que ocurre con la fijación del precio de cualquier otro producto. Y esto se cumple tanto para los bienes producidos por empresas públicas, como el actual sistema monetario, como para las privadas.

Una última explicación vendría por la posibilidad de expropiar los bienes de los nacionales del país para mantener el valor de la moneda. La experiencia pasada nos muestra que los políticos jamás afrontarán una medida tan impopular como hemos visto en los episodios de impago de deuda pública. Confiar que un político expropie a sus votantes para satisfacer la reclamación de un no votante es un argumento demasiado endeble para confiar en la moneda de un país. No hay más que ver la escasa aceptación de una moneda como el rublo que está respaldada por uno de los Estados con mayor riqueza en recursos naturales.

La verdadera explicación de la aceptación del dinero fiduciario es tan simple como la traslación de las causas expuestas por Menger del porqué los metales preciosos eran usados como dinero: cumplen mejor la función de facilitar los intercambios comerciales. A la moneda también se le exige que sea un depósito 
de valor pero ese aspecto no puede ser determinante ya que exigiría cambiar constantemente de referencia usando hoy el aluminio y mañana el cacao dependiendo de las cotizaciones. Existen muchas alternativas como depósitos de valor que van desde las materias primas hasta las inversiones inmobiliarias pero ninguna es mejor para su uso en las transacciones. El dinero debe ser un depósito de valor pero sobre todo tiene que ser la mejor alternativa al trueque.

IV

\section{TODO DINERO ES FIDUCIARIO}

Los detractores del dinero fiduciario no consideran al dinero como una mercancía con una utilidad propia. Mises (1949) no vio más que meros troquelados que no pueden ser utilizados para ningún propósito industrial ni servir de reclamación ante nadie, no considerando su función para facilitar los intercambios comerciales.

El dinero es un bien como cualquier otro. Satisface una necesidad de los consumidores, facilitar los intercambios comerciales, y por tanto tiene su propia demanda. Si el oro fuera usado exclusivamente para la fabricación de elementos ornamentales tendría una determinada demanda. Si el oro pasara a ser utilizado también como dinero, su demanda se incrementaría ya que no sólo los joyeros lo solicitarían sino también todo aquél que quisiera realizar compras en el mercado. La oferta de oro por el contrario resulta bastante inflexible. A pesar del aumento que se pueda experimentar en las explotaciones mineras del mineral, las reservas existentes no pueden lograr una multiplicación para atender al incremento de la demanda.

Un crecimiento de la demanda y un estancamiento de la oferta llevarían consigo un incremento del precio del oro. Por tanto, la nueva utilidad del oro supone un incremento de su valor provocado por la fe de los poseedores en que será aceptada por otros agentes en el intercambio comercial. Ese incremento de su precio será su valor fiduciario ya que dependerá de la fe en su uso como dinero. Cuando se utiliza al papel como soporte del dinero seguirá existiendo ese mismo valor fiduciario. La única 
diferencia es que el valor del soporte es mayor en el caso del oro que del papel. No se trata por tanto de ningún patrón-aire (Benegas 1998), sino del valor que les dan los consumidores por cumplir una funcionalidad como cualquier otro producto.

Mises exponía que los trozos de papel no tenían valor, ¿y lo tenía el oro? Si esos papeles cumplen una función, la de facilitar el intercambio, serán valorados por los usuarios en virtud de la utilidad que les procura. Hubo un tiempo en el que el oro no tenía ningún valor. Cuando ningún orfebre se había fijado en él para elaborar sus obras apenas eran pedruscos para unos humanos preocupados por recolectar frutos y cazar animales. De la misma manera que el papel no servirá más que para empapelar antes que un banquero lo marque y posibilite su función como dinero.

La valoración del oro recogerá la utilidad obtenida por los usuarios según sus funcionalidades (adorno, coleccionismo o como dinero) igual que la de las anotaciones de cuenta o papel, aunque estos últimos la práctica totalidad de la valoración corresponderá a su utilidad como dinero. Al final como el resto de los productos, el dinero será valorado más cuanto más útil sea a los usuarios. Un paraguas será más valorado cuanto más proteja de la lluvia a los viandantes mientras el dinero será más valorado cuanto mejor facilite el intercambio de productos en el mercado.

Mientras sea usado para el tráfico comercial, el valor del dinero fiduciario no puede vincularse exclusivamente al del papel que lo representa. Igual ocurre cuando valoramos una camiseta por el textil, un litro de bebida por la cantidad de agua y añadidos que contiene o un bolso por la piel con la que está hecho. Una camiseta con el logo de Nike no tiene el mismo precio en el mercado que una sin él. Un litro de bebida gaseosa oscura y dulce no tiene el mismo precio en el mercado con el logo de Coca-Cola o sin él. El mercado valora más un bolso con la marca Louis Vuitton que otro con el mismo material pero sin denominación.

Los consumidores están dispuestos a afrontar ese mayor precio por varios motivos. Uno de ellos es que la marca les proporciona información sobre si el producto va a satisfacer sus expectativas. Cuando alguien adquiere una botella de Coca-Cola sabe el sabor que le va a proporcionar, cuando adquiere una 
camiseta de Nike sabe cual va a ser su durabilidad y cuando adquiere un bolso de Louis Vuitton conoce su calidad. Si adquiriese esos productos sin ninguna marca no sabría a priori su sabor, su durabilidad o su calidad por lo que no conocería la utilidad que fuera a obtener. De la misma manera, si una persona adquiere un paquete de papeles no sabrá a priori si iba a lograr que le sirvieran para el intercambio de productos en el mercado. Si esos papeles tuvieran el logo de Dólar, Euro o Yen sabría que sí iban a servirle para comprar y vender sus productos. La reputación de los emisores de la moneda y su grado de aceptación vienen identificados por su «marca» como expuso Klein (1974).

\section{$\mathrm{V}$ \\ LOS RIESGOS DEL DINERO FIDUCIARIO}

En principio puede parecer chocante que alguien acepte un bien que no necesita a cambio de los productos que tanto esfuerzo le ha supuesto cazar, recolectar o fabricar. Surgiría el temor a sufrir algo parecido al juego infantil de la silla donde se corre en círculo hasta que se para la música y entonces se tiene que sentar en una silla. La gracia del juego consiste en que hay menos sillas que jugadores, por lo que uno de los jugadores no podrá sentarse y quedaría eliminado. Lo mismo podría ocurrir con el uso de las monedas. El comercio transcurriría normalmente pero si en un momento determinado se dejara de aceptar, aquellos que poseyeran dinero se encontrarían con un bien que no les aportaría ninguna utilidad. Se trata de un riesgo del dinero fiduciario, es decir, como hemos visto en el punto anterior es un riesgo de todos los dineros.

Se trata del miedo que utilizan algunos autores para la justificar el papel del estado para obligar el uso de una determinada moneda. Y es el mismo miedo que explica el argumento de que el dinero no puede alcanzar un valor por sí mismo ya que simplemente son trozos de papel. En un mundo donde el dinero electrónico está popularizando su uso dicho problema se agudiza. ¡Las anotaciones en cuenta situadas en un ordenador no sirven ni para empapelar una habitación! 
¿Qué ocurre si se para la música como en el ejemplo del juego de la silla expuesto anteriormente? Si su elección fue equivocada y los colectivos deben adaptarse a otra moneda para poder comerciar con un grupo más amplio. El colectivo habrá perdido todo lo invertido en sus monedas porque ya no tendrán ninguna utilidad y, por ende, ningún valor. Como en el caso citado del juego, si el oro dejara de ser usado como dinero, aquellos que lo posean exclusivamente para dicha utilidad pueden vendérselo a aquellos que lo demanden para otros usos como los ornamentales. Al producirse un aumento de vendedores de oro y una reducción de los compradores, el precio caería y por tanto se producirían importantes pérdidas para los tenedores de oro. ¿Sería menor esa pérdida si se poseyera papel o anotaciones electrónicas?

Los poseedores de papel moneda o de anotaciones en cuenta perderían todo su valor en caso que dejaran de ser utilizadas como dinero. La cuestión radica en que el precio de adquisición de ese dinero fiduciario sería mucho menor que el necesario para aprovisionarse de dinero-mercancía. Esa diferencia entre el precio de adquisición de ambos tipos de dinero puede ser invertida en una cartera diversificada que incluya inmuebles, máquinas o activos financieros. Por el contrario, los poseedores de oro tendrán el importe del sobre-precio del dinero-mercancía atrapado en una única mercancía idéntica a la de todos los agentes de ese sistema monetario con la caída en el precio que implica.

Imaginémonos dos situaciones. Un determinado colectivo A decide decantarse por el oro para dotarse de un sistema monetario que facilite los intercambios comerciales. Para adquirir suficiente oro para tal cometido acuden a una empresa minera. Por una parte la empresa minera se enfrenta a unos determinados costes para extraer el metal. Debe acometer importantes inversiones y competir con otras empresas para lograr personal dispuesto a asumir el trabajo. Por otra parte la empresa minera tiene otros clientes como empresas joyeras o de adornos decorativos que le están demandando sus productos de forma continua. Ante la nueva petición decide incrementar el precio ya que los proveedores del metal precioso son limitados debido al número reducido de minas de oro. Por todo esto, el colectivo A debe 
desembolsar 300 jornadas de trabajo para obtener el oro que les sirva como moneda.

Por otro lado, otro colectivo B se decide a encargar a una empresa informática la gestión de anotaciones en cuenta electrónicas. Existen numerosísimos proveedores en el mercado, los avances tecnológicos son continuos y las alternativas se multiplican. Por esta razón los miembros del colectivo apenas tienen que desembolsar un día de trabajo para obtener el sistema necesario para facilitar sus intercambios comerciales. Si la nueva moneda no tuviera éxito como unidad de intercambio, el colectivo B habría perdido todo lo invertido en el nuevo dinero.

Por el contrario si fueran los miembros del colectivo A los que tuvieran que cambiar sus monedas, verían con satisfacción que sí lograrían recuperar parte de lo invertido. Sus monedas son metales preciosos demandados por otros agentes que lo usan para otras funciones. Pero el precio del metal caería. Primero, por el descenso de la demanda al haber perdido su uso monetario. Después, porque aumentaría la oferta al sumarse los poseedores del oro como dinero a las compañías mineras. Todo esto provocaría una caída en el precio. Imaginemos que esa caída se ve limitada a un $10 \%$. ¿No está mal? No lo estaría si no fuera porque al final el colectivo $\mathrm{B}$ ha perdido un día de trabajo mientras el colectivo A ha perdido 270 días. Podemos comprobar que resulta más peligroso elegir un metal precioso, $u$ otro bien con diversas funciones, como dinero que elegir un bien cuyo uso exclusivo sea el monetario. A pesar de que en este último caso perdamos toda la cantidad invertida.

Si atendemos a las razones por las que se monetariza un bien que se detallan en la segunda parte del presente artículo, el dinero fiduciario, primero en papel y ahora en anotaciones en cuenta, cumple mejor las funciones de medio de intercambio en el mercado. El presunto riesgo de aceptar un dinero sin respaldo aurífero queda difuminado cuando comprobamos que las pérdidas son menores ante una desmonetarización que si hubiéramos optado por una moneda con respaldo en mercancías o metales preciosos y a su vez son más improbables, ya que se trata de un producto que cumple mejor la función de facilitar los intercambios. 
Puede aducirse que el dinero fiduciario no puede considerarse una evolución debido a que cada cambio histórico de un bien a otro como moneda lo realizaron los agentes libremente. Por el contrario, la eclosión del dinero fiduciario vino de la decisión unilateral de los gobiernos. Pero también eran esos mismos gobiernos los que legislaban sobre la anterior moneda respaldada por oro.

Si en un apartado anterior pudimos ver cómo la valoración del dinero fiduciario depende de la utilidad proporcionada a los consumidores y no de la obligación de su uso por parte del aparato estatal, nada impediría la existencia de dinero fiduciario privado. El dinero fiduciario sin respaldo gubernamental se presenta como alternativa al dinero-mercancía y al dinero fiduciario respaldado por el Estado. El dinero fiduciario no necesita tener un cordón umbilical con un Estado para aparecer ni para sobrevivir. Es cierto que apareció por una decisión gubernamental pero también se han producido casos en los que ha surgido de los agentes del mercado como en dos ejemplos que se presentan a continuación: el del Dólar Linden y el del Swiss Dinhar.

El primero de ellos es emitido por una empresa informática para su uso en uno de sus programas. Se trata de un juego de simulación en las que los jugadores asumen un determinado personaje en un mundo virtual y que se denomina Second Life. La interacción se produce con otros personajes controlados por otros jugadores contando numerosos participantes. Concretamente existen más de dos millones y medio de jugadores denominados residentes en la nomenclatura del juego.

$\mathrm{Al}$ recrear un mundo virtual alternativo, los programadores no han descuidado ningún detalle e incluso han creado una moneda propia, el dólar Linden, que permite adquirir bienes existentes en ese mundo. Pero el sistema no es como el de Paypal que actúa para facilitar las transacciones electrónicas y está denominado en dólares americanos, en este caso sirve como unidad de cuenta y de intercambio. El dólar Linden cotiza diariamente con el dólar americano y varía su precio igual que cualquier otra 
moneda. Por tanto aquellos que canjeen sus dólares americanos por dólares Linden se pueden encontrar con que la cotización haya cambiado cuando quieran volver a convertirlos a la moneda original, con la consiguiente pérdida o beneficio. La cotización dependerá de la demanda y la oferta de dólares Linden y no disponen de respaldo ni estatal ni material alguno.

Otro ejemplo de dinero fiduciario sin el respaldo del sistema jurídico de un Estado lo encontramos en la historia reciente de Irak. A diferencia del ejemplo anterior, no existía ningún organismo supervisor del funcionamiento de la moneda. Se produjo con posterioridad a la invasión de Kuwait que finalizó tras la actuación militar de una coalición de diversos países. Pero la derrota no supuso el final del régimen de Sadam Hussein que tuvo que enfrentarse a un bloqueo económico. Dicho bloqueo supuso no poder contar con la tecnología de una empresa suiza que anteriormente se ocupaba de la impresión de billetes. A partir de eso momento, el gobierno iraquí emitió nuevos dinhars de peor calidad y en gran cantidad, muy por encima de lo que hacía antes de la Primera Guerra del Golfo.

Ante esta situación la población iraquí no se deshizo de los antiguos billetes a pesar de que ya no eran de curso legal. Si los nuevos billetes eran de peor calidad y su número se multiplicaba cada poco de forma importante, los viejos billetes cumplían mejor la función de medio de pago. Concretamente cumplían mejor dos de las características necesarias del dinero que expusimos en el segundo apartado: eran más escasos y con una mayor durabilidad por su calidad de fabricación. Esto hizo que siguieran siendo utilizados por los iraquíes que pasaron a denominarlos Swiss dinhars, por su origen en una empresa del país helvético, distinguiéndose de los dinhars oficiales.

Se produjo una situación de competencia entre una moneda de curso legal por orden estatal y otra moneda utilizada por los ciudadanos pero sin respaldo material ni legal. La utilidad de uno y otro para los usuarios quedo clara en la cotización de cada moneda. La función de medio de pago las cumplía mejor el Swiss dinhar que el Dinhar oficial del gobierno iraquí por lo que el precio-cotización del primero superó ampliamente el segundo. Hasta el punto que en una vez desalojado Sadam Hussein del 
poder, la nueva autoridad emitió una nueva moneda que se canjeaba según la cotización de cada moneda. Cada viejo dinhar de la época Hussein se canjeó por un nuevo dinhar mientras cada Swiss dinhar se canjeó por 140 nuevos dinhars. El cambio reflejó el éxito de una moneda que no contaba con respaldo ni estatal ni en mercancías frente a una moneda gestionada por un gobierno.

Existen muchos otros casos de monedas fiduciarias que han sido aceptadas y usadas por el público durante un largo período de tiempo. Es el caso de las llamadas monedas locales aceptadas en pequeñas comunidades y que tienen por objeto incentivar los intercambios en una pequeña zona. Fue el caso de la moneda emitida en la localidad austriaca de Wörgl durante la década de los treinta que no disponía de respaldo alguno. El caso más excéntrico fue el del autoproclamado emperador de Estados Unidos Joshua A. Norton, que a pesar de sus irreales pretensiones logró que su dinero fuera aceptado en la ciudad de San Francisco. En la actualidad siguen existiendo monedas locales como los Dólares de Calgary o los Ithaca Hours. Resulta esclarecedor cómo en el apartado de preguntas frecuentes de la página web de estos últimos a la pregunta de si se trata de dinero real contestan que su moneda tiene el mismo respaldo que el dólar norteamericano: ninguno.

También existen iniciativas que tratan de fomentar el comercio mediante la creación de un sistema que de soporte al trueque como las denominadas LETS (Local Exchange Trade System). Algunas de esas monedas son promovidas como alternativas al sistema capitalista cuando realmente son las verdaderamente capitalistas al ser provistas por organizaciones privadas y no requerir imposiciones gubernamentales.

\section{VII}

\section{EL DINERO BANCARIO O DINERO CRÉDITO}

Algunos autores incluyen en la cantidad de dinero existente del sistema a determinados instrumentos financieros, como los depósitos bancarios. Selgin y White (1996) denominan a esos 
sustitutivos como «fiduaciary media» al estar respaldados por dinero base y diferenciarlo del «fiat money» o "dinero fiduciario» que sería el dinero base no respaldado por ningún otro bien. Esta diferenciación hace que autores como Huerta de Soto (1988) no defiendan la libertad de los bancos y sus clientes para llevar a cabo libremente los contratos que consideren adecuados. De esta manera postulan la obligatoriedad de que las entidades mantengan la totalidad del dinero depositado por los ahorradores como reservas de disposición inmediata para impedir la multiplicación del dinero en circulación.

Los individuos gastan en función de la riqueza que tienen y del dinero en metálico que poseen. Los depósitos a la vista forman parte de esa riqueza pero también otro tipo de bienes o derechos como los depósitos a plazo, los inmuebles o las acciones de empresas. En unos mercados cada más integrados existen cada vez un mayor número de bienes que pueden convertirse rápidamente en efectivo. De esta manera se pueden vender numerosos activos como acciones o bonos en un breve periodo de tiempo. Incluso los bienes inmuebles disponen de una alta liquidez en mercado pujantes por parte de grupos de inversores o a través de financiación con garantía hipotecaria. Esto lleva a los defensores de un concepto amplio del dinero a incluir cada día nuevos conceptos dentro de la masa monetaria. Si incluimos a los depósitos bancarios como dinero, ¿no tendríamos que incluir también numerosos bienes con una gran liquidez?

En el preciso momento en que un agente decide entregar una cantidad de dinero al banco a través de un contrato bancario lo que está haciendo es realizar un préstamo al banco. Que el plazo de vencimiento de dicho contrato no esté definido a priori no significa que no lo tenga. El cuentacorrentista puede solicitar la devolución de la cantidad entregada al banco en cualquier momento. De manera similar que el trabajador puede rescindir un contrato laboral indefinido que tenga suscrito con una empresa aunque en el momento de la firma no haya sido estipulada la fecha. La alternativa que tiene el cliente es depositar su dinero en una caja de seguridad que los bancos ofrecen con lo que estará disfrutando de un servicio de custodia y no realizando un préstamo a la entidad de crédito. 
Al dinero depositado en los bancos no lo deberíamos considerar dinero base sino como otro dinero diferente y alternativo. Si un agente quiere adquirir un bien con dinero no le servirá para nada poseer una cuenta corriente. Deberá retirar el dinero de la cuenta y entregárselo al vendedor. Otra cuestión diferente es que decida realizar el intercambio comercial sin dinero pero utilizando otros instrumentos. Una posibilidad es pagar con un derecho de cobro, por ejemplo con un depósito bancario o un pagaré de un tercero. El dinero no se hace efectivo durante la transacción. El derecho de cobro actúa como moneda, pero es otra moneda diferente y por tanto no tiene el mismo valor que la moneda original en la que está cuantificado ese derecho.

En el caso de un depósito nos encontraríamos con el siguiente caso. Un derecho de cobro de 100 unidades monetarias sobre un banco muy solvente, es decir con unas reservas elevadas y que presta el dinero a proyectos de escaso riesgo, tiene un valor superior del derecho de cobro de $100 \mathrm{u}$.m. de un banco poco solvente, es decir con unas reservas escasas y que presta el dinero a proyectos de elevado riesgo. Esa diferencia en la valoración radica en el mayor riesgo asumido en el segundo caso.

Si prefiriéramos no hacer efectivo ese derecho de cobro y decidiéramos endosarlo a nuestro banco habitual para incrementar nuestro depósito bancario, nos encontraríamos que su valor no es idéntico a su valor nominal. Para un banco 100 unidades monetarias nuevas suponen un incremento en sus reservas con lo que su solvencia aumenta y puede ofertar nuevos préstamos. Esto no ocurre cuando lo que le aporta el cliente es un derecho de cobro de otro banco que no pueda hacerlo efectivo por escasez de reservas, por lo que tenderá a «pagarlo» a un menor precio que si fuera dinero efectivo. Por tanto estamos hablando de diversos tipos de medios de intercambio con diferentes valoraciones. Por esa misma razón un comerciante avispado me proporcionaría más productos a cambio de 1000 unidades monetarias en dinero efectivo que a cambio de un cheque de mi cuenta por importe de un millón de u.m. Simplemente porque en ese segundo caso, todo lo que obtendría dicho comerciante sería una cifra menor a las 1.000 u.m. del primer caso. 
En los intercambios comerciales se producirán diversos precios. El precio del producto con el pago al contado en dinero será inferior que si el pago se realiza en depósitos bancarios, pagarés de terceros o compromisos de pago del comprador. No solo porque el cobro efectivo se realice a posteriori y por tanto se deban repercutir los intereses correspondientes, sino por la prima de riesgo derivada de que al final tanto el depósito como el pagaré pueden acabar siendo impagados y nunca lleguen a convertirse en dinero.

Si los bancos incrementan los créditos que conceden a cargo de disminuir sus reservas lo que estarán haciendo es provocando una reducción del valor de sus depósitos y por tanto un incremento del precio de los bienes que se pueden adquirir con esos depósitos. Lo que reduce es el poder adquisitivo de los poseedores de depósitos bancarios pero no el de los poseedores de dinero efectivo. La variación del valor de los depósitos dependiendo de la solvencia del banco es similar a las variaciones en la cotización de los valores de renta fija emitidos por la empresa a raíz de cambios en sus estados financieros.

Por su propio interés, el banco tratará de mantener una solvencia elevada manteniendo unas reservas elevadas y prestando el dinero a clientes de bajo riesgo. Y también por su propio interés, el cliente depositará su dinero en aquellos bancos más solventes para poder recuperar lo aportado cuando lo precise. El dinero depositado en un banco podrá ser utilizado como un medio de intercambio más, pero un medio diferente al dinero líquido no depositado.

No se cumple así lo establecido por Hoppe (1994) respecto a que la expansión crediticia aumenta la oferta monetaria y disminuye, por tanto, el poder adquisitivo de las unidades monetarias del resto de los tenedores de saldos de dinero ${ }^{3}$. Siguiendo el razonamiento anterior, un productor canjeará un determinado bien según la valoración que haga de la contraprestación. De esta manera aceptará 100 unidades monetarias de dinero, 101 u.m. de dinero depositado en un banco solvente o $240 \mathrm{u}$.m. si el banco

\footnotetext{
3 Páginas 70-71.
} 
depositario le inspira menos confianza. La valoración del endoso del depósito bancario fluctuará según la solidez financiera del banco pero no afectará a la valoración de las unidades monetarias no depositadas en ningún banco que seguirán siendo un número limitado.

La diferencia entre el dinero base y el dinero crédito es que el valor del primero depende de la demanda y de la pericia de la entidad emisora mientras el del dinero crédito dependerá de la solvencia de la entidad bancaria. Rolnick y Weber (1988) lo muestran en el caso de los dólares emitidos antes de la existencia de la Reserva Federal. Billetes con el mismo valor facial tenían diferente valor en el mercado dependiendo del nivel de reservas del banco emisor lo que no afectaba al valor del dinero base que en aquel momento era el oro.

\section{VIII}

\section{LA GESTIÓN DEL MEJOR DINERO POSIBLE}

El proceso de desnacionalización del dinero puede parecer complejo pero realmente no difiere de lo ocurrido con otros sectores. Hace años cada país tenía una compañía aérea denominada de bandera que poseía el monopolio en su área geográfica. Para los vuelos internacionales cada país realizaba acuerdos de reciprocidad por las cuales una compañía realizaba vuelos desde su país hasta otro, quien también poseía una compañía de bandera que hacía el mismo recorrido. Pero las compañías veían limitada su capacidad para realizar vuelos entre dos destinos sin que la salida o la llegada fueran en su país. Todo esto se resolvió con la privatización de dichas compañías y con la liberalización del sector. Los actuales bancos centrales poseen una importante imagen de marca que les proporciona reconocimiento en el mercado. Obtendríamos el modelo deseado si se privatizara la Reserva Federal, el Banco Central Europeo o el Banco Central Japonés y permitiéramos que cada moneda fuera utilizada más allá de sus fronteras.

Los dólares, yenes o euros emitidos por emisores privatizados partirían de la valoración de los antiguos dólares, yenes 
o euros públicos de la misma manera que los dólares fiduciarios a partir de Bretton Woods partieron del valor de los dólares respaldados por oro. Su evolución posterior ya dependerá de la pericia de los gestores. ¿Y cuál será el valor de las monedas de los nuevos emisores que se incorporen al mercado? Sería un caso similar a la salida de un nuevo producto al mercado o de las acciones de una nueva empresa a la bolsa. En ambos casos tiene un importante peso en su valoración las características de los productos sustitutivos. El precio de una nueva consola de videojuegos dependerá de la mejora que suponga sobre las existentes hasta la fecha y del precio de éstas. El precio de las acciones de una empresa que no cotice en bolsa dependerá de la rentabilidad ofrecida por las inversiones alternativas. Y la valoración de una nueva moneda dependerá de la confianza en el emisor, de sus características y de las monedas ya existentes.

Podemos comprobar cómo se llevaría a cabo todo esto retomando los ejemplos mostrados en el sexto apartado. El swiss dinhar comenzó teniendo la misma paridad que el dinhar oficial para después disfrutar de una mayor revalorización. Sería el equivalente a una moneda que fuera pública y que luego se privatizara. El caso del Dólar Linden de Second Life sería el de una moneda de nueva producción. Sus creadores instauraron un primer cambio arbitrario: 300 dólares linden por un dólar americano. Como se puede apreciar en el Gráfico 2, la horquilla entre la cotización máxima y mínima diaria fue enorme al comienzo de su circulación hasta estabilizarse alrededor de un rango superior al estipulado en su nacimiento.

La estabilización de la cotización se alcanzó a pesar del crecimiento exponencial de la comunidad de Second Life que provoca una presión compradora de Linden Dólar en perjuicio del Dólar Americano. Pero esto no se traduce en una revalorización del Linden Dólar debido a que los creadores están aumentando la masa monetaria al ritmo que crece la economía de Second Life al más puro estilo de un banco central. De la misma manera que la gestión de las monedas recaería en sus emisores que ya no serían los bancos estatales.

¿Cómo se gestionaría ese dinero? Cada uno de los emisores lo haría según los criterios que consideraran más conveniente. 
GRÁFICO 2

EVOLUCIÓN DE LA COTIZACIÓN DEL DÓLAR LINDEN FRENTE AL DÓLAR NORTEAMERICANO

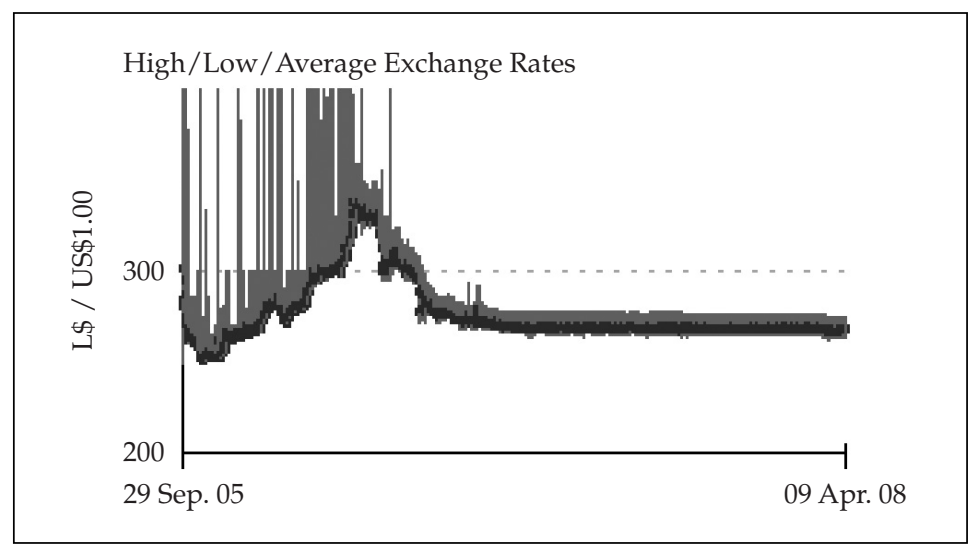

Fuente: Seconlife.com

Se abriría así un amplio abanico de posibilidades y sería la evolución de la moneda la que marcaría su bondad o no. Por ejemplo, Alchian y Klein (1973) defendían un crecimiento de la masa monetaria en base a la inflación y Friedman (1969) postulaba un incremento en porcentajes fijos. Hayek (1978) argumentó a favor de ligar la valoración de las monedas a la cotización de una cesta de materias primas. Otras opciones podrían ser la congelación de la cantidad de dinero emitido o dejar al arbitrio de los gestores los incrementos de masa monetaria.

La idea de una masa monetaria fija es la que dota de una mayor estabilidad y certidumbre a la valoración de una moneda, aspectos vitales para facilitar el intercambio comercial. La experiencia dice que la cantidad de dinero tiende a reducirse debido a pérdidas como por ejemplo por deterioro del soporte o fallecimiento de los poseedores. Por tanto sería deseable una tasa, sino de crecimiento, sí de restitución de la masa monetaria para evitar su reducción paulatina y continua. Estas disposiciones no deberían encorsetar la capacidad de los gestores para modificar la cantidad de dinero emitido cuando pretendan introducir sus monedas 
en nuevas zonas geográficas o fusionarse con otros emisores. Es probable con esta gestión se produjera una deflación, lo que no tiene porque ser perjudicial para la economía como muestra Selgin (1997).

Algunos autores como Kindleberger (1978) defienden el monopolio estatal de la emisión de moneda por su carácter de bien público. Incluso Hayek indicó en 1986 la necesidad de una cierta estandarización por la imposibilidad de que el consumidor se enfrentara a un mercado con precios en varias monedas para los mismos productos. Craig y Waller (2000) exponen cómo el dólar ha estado compartiendo determinados mercados con monedas locales sin ningún impedimento al comercio en diferentes monedas. También cabe recordar el caso de Andorra donde en el pasado circulaban simultáneamente la peseta española y el franco francés mientras florecía el comercio. Incluso en la actualidad, que los precios en Estados Unidos estén referidos en dólares no impide a un gran número de europeos realizar compras en ese país.

Monnet (2006) duda que otros agentes aparte del gobierno tengan incentivos para emitir moneda. Nada impide que se obtenga lucro con la gestión de la moneda. En la actualidad, la gestión del dinero por parte de los bancos centrales estatales está provocando una pérdida de poder adquisitivo para sus poseedores. Si los emisores libres lograran mitigar esa pérdida a cambio de una contraprestación económica, los consumidores elegirían sus monedas. También existen otras alternativas como mutualidades de entidades de crédito, al ser su negocio muy sensible a la calidad de la moneda que utilizan, u otro tipo de asociaciones. Así, las actuales monedas sin intervención estatal censadas por el Complementary Currency Resource Center están gestionadas en un $48 \%$ por asociaciones, un $47 \%$ por empresas privadas y un $5 \%$ por cooperativas.

\section{IX CONCLUSIÓN}

Si dejáramos a libre arbitrio de los individuos la elección de la moneda sería la evolución de las diferentes alternativas las que determinaría el modelo resultante. En un principio podrían surgir 
innumerables nuevos proyectos cada uno con sus propias características. De esta manera podría haber quien lanzara una moneda con el respaldo del oro o de otra mercancía. Mientras en el sector bancario surgirían entidades que ofrecieran la reserva de la totalidad de los depósitos de sus clientes y habría otros temerarios que mantendrían reservas mínimas.

Hayek ya advirtió en 1978 que «siempre hemos tenido dinero malo porque nunca se ha permitido a la empresa privada ofrecernos otro mejor». De la misma manera anhelaba el «día aquel en el que no tengamos que depender de la benevolencia del gobierno para tener buen dinero, sino en la preocupación de los bancos por su propio interés» ${ }^{4}$. En la actualidad tenemos que padecer la pérdida de valor de nuestro dinero ante la imposibilidad de utilizar un mejor medio de intercambio. Pero ligar ese dinero bueno a determinadas mercancías no supone ninguna mejora y sí un importante lastre.

Un gran número de materiales han sido utilizados como dinero a lo largo de la historia. Se fueron sustituyendo según se descubrían materiales que cumplían mejor las características necesarias para servir como dinero y facilitar el intercambio de productos. Los metales preciosos fueron utilizados como dinero durante un largo período de tiempo hasta que se generalizó el uso de bienes de escaso valor como moneda, el denominado dinero fiduciario.

El paso de un dinero basado en oro al dinero fiduciario fue decidido por los gobiernos. Los críticos de tal medida argumentan que sin la coacción legal de los Estados los agentes nunca hubieran abandonado los metales preciosos como dinero. Pero el dinero fiduciario simplemente cumple mejor las funciones que reclaman los usuarios de la misma forma que el oro las cumplía mejor que las conchas de mar.

Las taras que tiene el actual dinero fiduciario, que las tiene, no son derivadas de su naturaleza. Cuando eran los gobiernos los encargados de acuñar las monedas de oro, los usuarios también tenían que padecer un dinero malo en muchas ocasiones, como por ejemplo cuando se producían rebajas en el metal

\footnotetext{
${ }^{4}$ [Trad. esp. (2001). Ensayos de Teoría Monetaria II, Madrid, Unión Editorial, p. 301].
} 
que contenían las monedas. Algo similar ocurre con el dinero fiduciario donde los ciudadanos también tienen que sufrir la mala gestión de los estados. Es la libertad de elegir la moneda lo que permite a los agentes disponer de la mejor posible.

Surgen dudas a la hora de valorar el dinero fiduciario. La verdad es que no se distingue demasiado de la valoración del resto de bienes y servicios por lo que dependerá de la utilidad apreciada por los usuarios. Lo que ocurría en el caso del oro es que se solapaban dos utilidades, la que proporcionaba como dinero basado en la fe de que sería aceptado en el intercambio comercial, y como elemento ornamental. El dinero llamado fiduciario sirve únicamente como moneda por lo que se valora por su única utilidad. Pero eso no supone que tenga un mayor riesgo ni que no se pueda valorar.

Si el dinero fiduciario es valorable y sus características cubren mejor las necesidades requeridas a la moneda, es necesario liberarlo del monopolio estatal. Hay experiencias que muestran la viabilidad de un dinero fiduciario independiente de la tutela de los gobiernos como son el caso de la comunidad virtual Second Life o lo ocurrido en Irak con los Swiss dinhar. Ha habido otros sectores que históricamente fueron monopolizados por los gobiernos y que posteriormente se mostró que podían ser gestionados mejor por los agentes. Nada impide que eso ocurra también con el dinero fiduciario.

El dinero depositado en bancos es aceptado en muchas ocasiones en el intercambio de productos. Pero el valor de ese dinero depositado dependerá de la gestión realizada por el banco correspondiente. No podemos olvidar que se trata de un derecho de cobro y como tal no afecta a la valoración del dinero base. Que exista un número elevado de depósitos afectará a la valoración del dinero depositado pero nunca al dinero base cuya cuantía es independiente.

Hemos comprobado que el dinero fiduciario ha supuesto un avance técnico que cubre mejor los requisitos que se le pide a la moneda que otros materiales. Combinando las ventajas de un sistema de moneda libre con las ventajas del dinero fiduciario aparece la defensa del dinero fiduciario independiente como el más eficiente para facilitar el intercambio de productos en el 
mercado. Para lograrlo simplemente hay que devolver el dinero a los ciudadanos para que ellos decidan. Devolvamos el dinero a la gente para facilitar más el comercio y lograr una mayor prosperidad para todos. Pero defender a las monedas con respaldo de materias primas o metales preciosos como alternativa a las monedas estatales fiduciarias es como defender la desnacionalización del ferrocarril postulando la vuelta de las diligencias de caballos.

\section{REFERENCIAS BIBLIOGRÁFICAS}

AlCHIAN, A.A. y B. Klein (1973): «On a correct measure of inflation». Journal of Money, Credit and Banking, vol. 5, n. 1, pp. 173-191. Anderson, B.M. (1925): «Gold Standard vs. Manager Currency», Chase Economic Bulletin, (trad. esp. [2004] «Moneda administrada frente a Patrón oro». Procesos de Mercado, n. ${ }^{\circ}$ 1, vol. I, Primavera, pp. 273-303).

BENATI, L. (2008): «Investigating inflation persistence across monetary regimes». European Central Bank Working Paper Series, n. 851.

BenEgas, A. (1998): «La moneda en una sociedad abierta». Economica, Año XLIV, n.o 4, Tomo II.

Craig, B.R. y Waller, C.J. (2000): «Dual-Currency Economies as Multiple-Payment Systems», Cleveland, Economic Review Federal Reserve Bank of Cleveland.

De Grauwe, P. y Polan, M. (2005): «Is Inflation Always and Everywhere a Monetary Phenomenon?» Scandinavian Journal of Economics 107 (2), 239-259.

Friedman M. y Schwartz, A.J. (1963): A Monetary History of the United States, 1867-1960. Princeton University Press.

Friedman, M. (1968): Dollars and Deficits: Living with Amercia's Economic Problems, Englewood Cliffs NJ, Prentice Hall.

- (1969): The optimun quantity of money, Chicago, Aldine.

- (1987): «Monetary Policy: Tactics versus Strategy». The Search for Stable Money, Chicago, University of Chicago Press, James A. Dorn y Anna J. Schwartz (ed.), pp. 361-382.

GARrison, R.W. (2001): Time and Money. The Macroeconomics of Capital Structure, Nueva York, Routledge. 
Greenfield, R.L. y Yeager, L.B. (1983): «A Laisez Faire Approach to Monetary Stability». Journal of Money, Credit and Banking, Ag., 15, pp. 302-315.

HAYEK, F.A. (1943): «A Commodity Reserve Currency». Economic Journal, vol. 53, n. ${ }^{-}$210/211, Jun. - Sep., pp. 176-184.

- (1978): Denationalisation of Money, Londres, Institute of Economic Affaire. (trad.esp. [2001]. Ensayos de Teoría Monetaria II, Madrid, Unión Editorial, pp. 187-304).

- (1986): «Market Standards for Money», Economic Affairs, vol. 6, n. 4, pp. 8-10.

Hodrick, R., Kocherlacota, N. y Lucas, D. (1991): «The Variability of Velocity in Cash-in-Advance Models». Journal of Political Economy, n. 99, 358-384.

Hoppe, H.H. (1994): «How is Fiat Money Possible? -or, The Devolution of Money and Credit». The Review of Austrian Economics. vol. 7. n. $\stackrel{-}{2}$. pp. 49-74.

Huerta De Soto, J. (1998): Dinero, crédito bancario y ciclos económicos, 4. a ed., Unión Editorial, Madrid 2009.

Kindleberger, C.P. (1978): Manias, panics and crashes, New York, Basic Books.

KeLIN, B. (1974): «The competitive Supply of Money». Journal of Money, Credit and Banking, 6, November, pp. 423-453.

Menger, C. (1892). «On the origin of money». Economic Journal, vol. 2, n. 6, pp. 239-255.

Mises, L. vON (1912): Theories des Geldes und der Umlaufsmittel. Munich, Dunker \& Humblot. (Edición española de Unión Editorial, Madrid 1997).

- (1949): Human Action: A Treatise on Economics, Londres, Willian Hodge. (9. a ed. española, Unión Editorial, Madrid 2009).

Monnet, C. (2006): «Private versus Public Money», International Economic Review, vol. 47, n. 3, pp. 951-960.

Rodríguez, H. (2006): «The Behavior of Money Velocity in Low and High Inflation Countries», Journal of Money, Credit and Banking 38 (1), pp. 209-228.

RODNICK, A.J. y WARREN, W.E. (1988): «Explaining the demand for free bank notes», Journal of Monetary Economics, vol. 21, n. 1, pp. 47-71. 
SELGIN, G. (1988): The theory of Free banking Money Supply under competitive Note Issue, Washington D.C., Rowman and Littlefield Publishers.

- (1997): Less than zero: the case for a falling price level in a growing economy, IEA HobartPaper, n. ${ }^{\circ}$ 132, The Institute of Economic Affairs, April.

Selgin, G. y White, L.H. (1996): «In defense of Fiduciary or, We are Not Devo(lutionist), We are Misesinas!» The Review of Austrian Economics, vol. 9, n. 2, pp. 83-107.

SMith, A. (1776): An Inquiry into the Nature and Causes of the Wealth of Nations, Londres. (Trad. esp. de Carlos Rodríguez Braun [2001] La riqueza de las naciones. Madrid, Alianza Editorial).

TAYLOR, J.B. (1993): «Discretion versus Policy Rules in Practice», Carnegie-Rochester Conference Series on Public Policy, n. ${ }^{-}$39, pp. 195-214. 